\title{
A VIOLÊNCIA CONTRA A MULHER, A CRIANÇA E O ADOLESCENTE COMO CAUSA DA PERDA DO PODER FAMILIAR Â LUZ DA LEI No 13.715/2018
}

\author{
Ana Radig Denne Lobão Morais ${ }^{1}$ \\ Naiara Cristina Costa da Silva Leite ${ }^{2}$
}

\section{Resumo:}

O presente artigo analisa a violência praticada no âmbito familiar contra a mulher na condição de detentora do poder familiar, contra a criança e contra o adolescente praticada pelo (a) outro (a) detentor (a) do poder familiar como causa para a perda deste poder por parte do agressor. A metodologia utilizada é a pesquisa bibliográfica, utilizando como fonte principal a Lei $\mathrm{n}^{\circ}$ 13.715/2018 e a doutrina especializada na área do direto de família.

Palavras-chave: perda do poder familiar, violência intrafamiliar, mulher, criança, adolescente.

\section{VIOLENCE AGAINST WOMEN, CHILDREN AND ADOLESCENTS AS CAUSES THE LOSS OF FAMILY POWER IN THE LIGHT OF LAW No. 13.715 / 2018}

\begin{abstract}
This article analyzes family violence against women as family power children and adolescente committed by the other family power holders as a cause for their loss power by the agressor. The methodology used is bibliographic research, using as its main source law $13.715 / 2018$ and doctrine specialized in the área of family law.
\end{abstract}

Key words: loss of Family power, intrafamily violence, woman, child, adolescent.

\section{INTRODUÇÃO}

$\mathrm{O}$ artigo, estudo intitulado "A violência contra a mulher, a criança e o adolescente como causa da perda do poder familiar à luz da Lei $n^{\circ} 13.715 / 2018$ " objetiva analisar a violência contra a mulher e contra os filhos e demais descendentes do agressor como causa da perda do poder familiar, tendo por parâmetro a Lei no 13.715/2018, a qual ampliou os tipos de violência que têm como consequência a medida extrema a respeito da retirada do exercício do poder familiar do agressor.

\footnotetext{
${ }^{1}$ Mestranda em Direito, Políticas Públicas e Desenvolvimento Regional pelo Centro Universitário do Estado do Pará - CESUPA, vinculada ao Programa Suporte à Pós-Graduação IES Particulares (PROSUP).

${ }^{2}$ Mestranda em Direitos Humanos pelo Centro Universitário do Estado do Para (CESUPA), na linha de pesquisa Direito, Ambiente e Desenvolvimento Regional (2019), nas condicionantes para licenciamento ambiental para exploração mineral e recuperação florestal das áreas ocupadas diretamente pelos projetos de mineração e as áreas no entorno, do Estado do Pará. Bacharel em Direito pela Universidade da Amazônia (2013). Advogada Sócia no escritório Naiara Leite Advocacia e Assessoria Jurídica.
} 
A Lei em comento inclui, dentre outras formas de violência, a violência doméstica e familiar; o feminicídio e o menosprezo ou discriminação à condição de mulher, dando ênfase à mulher como vítima de violência no ambiente familiar como práticas que levam à perda do poder familiar do agressor, e para alcançar o objetivo proposto, abordaremos a criança, o adolescentes e a mulher vítimas de violência como sujeitos vulneráveis na dinâmica familiar e, por esse motivo, detentores de direitos específicos que almejam a proteção destes contra a violência em âmbito doméstico e, caso esta violência não seja evitada, tenha-se por consequência a destituição do poder familiar do agressor, sendo o problema de pesquisa: há justificativa para a perda do poder familiar motivado pela prática de violência que vitime o outro detentor deste poder?

Optamos por analisar apenas as formas de violência contra as crianças, adolescentes e mulheres no seio familiar, apesar de reconhecer que a violência, no que tange aos detentores do poder familiar, não tem como vítimas exclusivamente as mulheres e que a lei em comento trata de forma igual tanto o homem quanto à mulher detentores do poder familiar, de maneira que ambos podem ser agressores e vítimas da violência que tem por consequência a destituição do poder familiar do agressor.

A escolha em dar ênfase à mulher como vítima se justifica no fato de que, para este estudo, será analisado o avanço da proteção à mulher contra as violências sofridas no ambiente familiar, bem como será apresentado dados estatísticos de agressões, homicídios e feminicídios no país, almejando justificar a importância do destaque dado à mulher na condição de vítima do outro detentor familiar, situação que, no mínimo, demonstra a existência de uma convivência conflituosa ao extremo que passou a ser violenta, o que intuise ser um ambiente danoso e até perigoso para as crianças e adolescentes desta família, sendo este fato uma das justificativas para a perda do poder familiar.

Analisaremos, no mesmo sentido, mediante a possibilidade de adoção em conjunto por casais constituídos por pessoas do mesmo sexo e em respeito ao princípio da isonomia entre todas as composições familiares, a aplicação da Lei Maria da Penha em casos de violência doméstica entre casais homoafetivos femininos, tendo em vista que para a incidência da Lei em comento ser irrelevante o sexo do agressor, importando apenas o da vítima e as consequências desta violência no poder familiar dos filhos do casal.

As principais referências teóricas são: Kátia Regina Maciel, na obra intitulada "Curso de Direito da Criança e do Adolescente: aspectos teóricos e práticos; Rolf Madaleno, no livro 
intitulado Direito de Família; Flávio Tartuce e Maria Helena Diniz e a metodologia utilizada será a pesquisa realizada mediante a análise da teoria, legislação e documentos internacionais pertinentes ao tema estudado.

Este artigo é estruturado da seguinte maneira: no primeiro item consta a introdução; no segundo será analisada a violência intrafamiliar praticada contra crianças, adolescentes e mulheres, de forma a esclarecer quais leis protegem estes sujeitos e qual a justificativa da necessidade de proteção específica a estas vítimas; no terceiro item será investigada a destituição do poder familiar à luz da Lei $\mathrm{n}^{\circ}$ 13.715/2018, a qual aumentou as hipóteses de destituição do poder familiar e deu destaque à mulher como vítima da violência intrafamiliar e, por fim, será apresentada a conclusão, na qual será respondido o problema de pesquisa, que orbita no questionamento a respeito das motivações que levam ao agressor perder o poder familiar nos casos em que a violência praticada não são contra a criança e o adolescente que estão sob o cuidado daquele.

\section{CRIANÇAS, ADOLESCENTES E MULHERES: LEGISLAÇÃO DE PROTEÇÃO CONTRA VIOLÊNCIAS INTRAFAMILIARES}

As relações familiares tem por característica a dinamicidade, o que por consequência torna as normas que regem juridicamente as interações sociais decorrentes deste vínculo familiar mutáveis. O ramo do direito denominado direito de família tem como atributo ser de direito privado, apesar de conter preceitos de ordem pública, dentre eles a limitação dos poderes dois pais no que tange ao tratamento e criação dos filhos, estando assim o poder familiar limitado a normas protetivas à crianças e adolescentes.

A família, no que tange à legislação brasileira, é fundada em uma cultura patriarcal, na qual a figura masculina é preponderante à figura feminina, com mais direitos e liberdades, tendo sido a mulher, por muito tempo, invisibilizada. Sobre este fato, Maria Berenice Dias, em capítulo intitulado "Situação Jurídica da Mulher" afirma que "a presença da mulher é uma história de ausência" (DIAS, p. 111, 2018).

A Constituição Federal de 1988 consagrou o princípio da igualdade entre homens e mulheres em direitos e obrigações (BRASIL, art. 5, I, 1988), deixando formalmente no passado uma longa história de submissão feminina e violências pautadas na posição inferior que a mulher ocupava na sociedade e dentro das famílias. 
No mesmo sentido, crianças e adolescentes possuem um passado obscuro no que tange à garantia de direitos na legislação brasileira, de forma que somente na Constituição Federal de 1988 alcançaram o status de sujeitos de direitos, tendo a Lei Magna inaugurado a doutrina da Proteção Integral e a corresponsabilidade entre família, sociedade e Estado de assegurar à criança, ao adolescente e ao jovem direitos fundamentais e os colocar a salvo de violações a estes direitos, ou seja, toda forma de negligência, discriminação, exploração, violência, crueldade e opressão (BRASIL, art. 227, 1988).

Por conseguinte, o poder familiar exercido pelos pais possui limites que devem ser respeitados, sendo este poder familiar também um dever de cuidado, educação, proteção, dentre outros e "tem como prioritário foco constitucional os melhores interesses da criança e do adolescente, e não mais a supremacia da vontade do pai, chefe da sociedade familiar" (MADALENO, 2018, p. 707).

Apesar da modificação de paradigma legislativo no que tange à violência contra a mulher, a criança e o adolescente, inclusive no ambiente familiar, consideramos que apenas a mudança da lei ao garantir direitos e punir aqueles que os violam não é o suficiente, tanto que os índices ${ }^{3}$ das mais variadas formas de violências contra estes sujeitos, no Brasil, são alarmantes apesar das inúmeras leis protetivas que serão analisadas a seguir.

Neste estudo almejamos analisar as relações familiares em uma perspectiva de violências sofridas por crianças, adolescentes e mulheres, mediante o reconhecimento de que estes sujeitos possuem vulnerabilidades físicas, econômicas e afetivas em relação ao agressor, que neste caso é a figura masculina no ambiente familiar, seja ele marido/companheiro, pai, avô, entre outros, tendo como contribuição para esta percepção a respeito da existência de violência intrafamiliar, Vivian Peres Day et alii afirma que:

\begin{abstract}
A hipótese de que o ambiente familiar, pelas ligações afetivas, protegeria seus membros mais vulneráveis, tem se mostrado bastante falha. Os crimes cometidos por doentes mentais de grande repercussão social e na mídia passavam a falsa ideia de que atos dessa natureza seriam atos de exceção cometidos por psicóticos, de forma imprevisível, restritos a situações raras, infortúnios de difícil prevenção (DAY, 2003, p.10).
\end{abstract}

\footnotetext{
${ }^{3}$ De acordo com dados do $12^{\circ}$ Anuário Brasileiro de Segurança Pública, em 2017 foram registrados 221.238 casos de lesão corporal dolosa enquadrados na Lei Maria da Penha (ou seja, violência doméstica e familiar), o que representa uma média de 606 casos por dia. Fonte: https://dossies.agenciapatriciagalvao.org.br/violencia-emdados/por-dia-606-casos-de-lesao-corporal-dolosa-enquadrados-na-lei-maria-da-penha/. No mesmo ano houve 4.539 homicídios de mulheres, desse total, 1.133 foram registrados como feminicídio e foram contabilizados 60.018 estupros contra mulheres. Fonte: https://dossies.agenciapatriciagalvao.org.br/dados-efontes/pesquisa/12o-anuario-brasileiro-de-seguranca-publica-fbsp-2017/.
} 
A Convenção Interamericana para Prevenir, Punir e Erradicar a Violência contra a Mulher - Convenção de Belém do Pará”, adotada pela Assembleia Geral da Organização dos Estados Americanos em 06 de julho de 1994 e ratificada pelo Brasil em 27 de novembro de 1995, afirma que a violência contra a mulher constitui violação dos direitos humanos e das liberdades fundamentais e limita total ou parcialmente à mulher o reconhecimento, gozo e exercício de tais direitos e liberdades, e reconhece que a violência contra a mulher é uma ofensa à dignidade humana e uma manifestação de relações de poder historicamente desiguais entre mulheres e homens.

Como enfatizado na introdução, não ignoramos o fato de tanto homens quanto mulheres terem a possibilidade de ocupar a posição de vítimas e a posição de agressores em violências ocorridas no âmbito doméstico. Entretanto, para este estudo, não analisaremos a violência praticada por mulher contra homem, pois daremos ênfase ao estudo da Lei $n^{\circ}$ 13.715/2018 que, ao aumentar as hipóteses de destituição do poder familiar incluindo a violência contra o outro detentor do poder familiar, na nossa interpretação, destacou a violência contra a mulher nesta situação, utilizando para tanto termos presentes na Lei do Feminicídio (Lei n ${ }^{\circ}$ 13.104/2015).

A Lei que dispõe especificamente sobre a perda do poder familiar em comento, portanto, dá destaque à violência contra a mulher ao lado da violência contra crianças e adolescentes no âmbito familiar como práticas que levam à perda do poder familiar do agressor, o que será explanado com mais profundidade no momento oportuno deste estudo.

Consideramos que a Lei $\mathrm{n}^{\circ}$ 13.715/2018 apresenta uma resposta aos números alarmantes de violência contra a mulher praticado por companheiros, namorados, maridos e outros homens ou mulheres que possuem proximidade familiar e afetiva com as vítimas, assim como o instituto da perda do poder familiar, anteriormente a esta Lei, já reconhecia a existência de violências intrafamiliares praticadas contra crianças e adolescentes e a dinâmica desta violência no que tange ao poder dos adultos exercido contra os descendentes.

Para ilustrar a respeito da existência de legislação que protege crianças, adolescentes e mulheres contra a violência intrafamiliar, apresentaremos primeiramente a Lei $n^{\circ} 11.340 / 2006$ (Lei Maria da Penha) e a Lei no 13.104/2015 (Lei do Feminicídio), dando realce à violência contra a mulher e posteriormente a Lei nº12.318/2010 (Lei da Alienação Parental) Lei no 
13.010/2014 (Lei Menino Bernardo) e a Lei $n^{\circ}$ 13.431/2017, que dispõe sobre o sistema de garantia de direitos da criança e do adolescente vítima ou testemunha de violência.

A Lei $n^{\circ} 11.340 / 2006$, conhecida como Lei Maria da Penha ${ }^{4}$, cria mecanismos para coibir a violência doméstica e familiar contra a mulher, alterando o Código de Processo Penal, o Código Penal e a Lei de Execução Penal e afirmando que "cabe à família, à sociedade e ao poder público criar condições necessárias para o efetivo exercício dos direitos enunciados no caput do art. $3^{\circ}$ da Lei” (BRASIL, 2006, $\S 2^{\circ}$ art. $3^{\circ}$ ).

O caput do art $3^{\circ}$ da Lei Maria da Penha disciplina, portanto, a corresponsabilidade entre a família, a sociedade e o Estado na defesa dos diretos assegurados às mulheres, os enumerando da seguinte maneira:

Serão asseguradas às mulheres as condições para o exercício efetivo dos direitos à vida, à segurança, à saúde, à alimentação, à educação, à cultura, à moradia, ao acesso à justiça, ao esporte, ao lazer, ao trabalho, à cidadania, à liberdade, à dignidade, ao respeito e à convivência familiar e comunitária (BRASIL, 2006, art. $3^{\circ}$ ).

A lei em comento têm por sua premissa maior o direito das mulheres de "gozar dos direitos fundamentais inerentes à pessoa humana, sendo-lhes asseguradas as oportunidades e facilidades para viver sem violência, preservar a sua saúde física e mental e seu aperfeiçoamento moral, intelectual e social” (BRASIL, 2006, art. $2^{\circ}$ ).

À vista disso, compreende a violência contra a mulher de uma perspectiva ampla, reconhecendo e conceituando as seguintes formas de violência doméstica e familiar, em um rol exemplificativo: violência física; violência psicológica; violência sexual; violência patrimonial e violência moral (BRASIL, 2006, art. $7^{\circ}$ ).

A violência doméstica ou familiar contra a mulher configura-se, portanto, como qualquer ação ou omissão baseada no gênero que lhe cause morte, lesão, sofrimento físico, sexual ou psicológico e dano moral ou patrimonial (BRASIL, 2006, art. $5^{\circ}$ ) que ocorra no âmbito da unidade doméstica; no âmbito da família ou em qualquer relação íntima de afeto presente ou passada, independente de coabitação (BRASIL, 2006, art. 5 , I,II e III).

\footnotetext{
${ }^{4}$ Maria da Penha é uma vítima real da violência ocorrida no âmbito familiar. Em 1983 foi vítima de dupla tentativa de feminicídio por parte do marido. Na primeira tentativa, ele deu um tiro nas suas costas enquanto ela dormia, o que a deixou paraplégica. Quatro meses depois, quando Maria da Penha voltou pra casa - após duas cirurgias, internações e tratamentos - ele a manteve em cárcere privado durante quinze dias e tentou eletrocutá-la durante o banho. Para mais informações, acessar o sítio eletrônico: http://www.institutomariadapenha.org.br/quem-e-maria-da-penha.html.
} 
A lei dispõe ainda sobre a assistência à mulher em situação de violência doméstica e familiar; os procedimentos; as medidas protetivas de urgência (tanto as que obrigam o agressor quanto as direcionadas à ofendida); a atuação do Ministério Público; a assistência judiciária e dá outras providências, afirmando também que as relações pessoais que caracterizam a violência doméstica e familiar independe da orientação sexual (art. $5^{\circ}$ parágrafo único).

Apesar de a Lei em tela vigorar há mais de doze anos, os números de casos de violência contra a mulher são inquietantes, como já demonstrado acima com dados do ano de 2017 sobre os números de registros de lesão corporal dolosa enquadradas na Lei Maria da Penha; de registros de feminicídios e de estupros.

Consideramos que antes de a Lei que cria mecanismos para coibir algum tipo de violência de fato alcançar o seu escopo, esta irá trazer à tona a existência desta violência mediante as denúncias, apurações e condenações pelos crimes tipificados. Isto se aplica sobremaneira aos casos da violência contra a mulher, violências estas que são historicamente invisibilizadas, de forma que essa invisibilidade se potencializa em ambiente doméstico ou familiar.

Neste contexto de reconhecimento da existência da violação de direitos da mulher mediante a violência, muitas das vezes letais, a Lei $\mathrm{n}^{\mathrm{o}}$ 13.104/2015 - Lei do Feminicídio ${ }^{5}$ altera o artigo 121 do Código Penal, prevendo o feminicídio como circunstância qualificadora do crime de homicídio e o art. $1^{\circ}$ da Lei $\mathrm{n}^{\circ}$ 8.072/1990 (Lei dos crimes hediondos) para incluir o feminicídio no rol dos crimes hediondos.

A qualificadora do crime de homicídio nos casos de feminicídio será aplicada quando o crime for cometido contra a mulher por razões da condição de sexo feminino (BRASIL, 2015, art. $1^{\circ}$ ), ou seja, quando o crime envolve violência doméstica e familiar e/ou menosprezo ou discriminação à condição de mulher.

Assim sendo, tanto a Lei Maria da Penha quanto a Lei do Feminicídio reconhecem que a violência contra a mulher ocorre, também, no ambiente familiar e doméstico, ocasiões nas quais os agressores possuem graus de intimidade e proximidade com a vítima, não sendo raras

\footnotetext{
${ }^{5}$ Sobre o número de notificações entre o dia $1^{\circ}$ de janeiro de 2019 e 04 de fevereiro do mesmo ano, a Comissão Interamericana de Direitos Humanos - CIDH - expressou sua preocupação pela prevalência alarmante de assassinatos de mulheres no Brasil, uma vez que pelo menos 126 mulheres foram mortas no país e 67 tentativas de feminicídio, no período citado acima. O Comunicado de imprensa foi veiculado no sítio eletrônico da Organização dos Estados Americanos - OEA em 04 de fevereiro de 2019. Para mais informações, acessar: http://www.oas.org/pt/cidh/prensa/notas/2019/024.asp.
} 
os casos nos quais a vítima se considera impossibilitada de denunciar as agressões ou sair da dinâmica da violência por depender financeiramente do agressor, por medo de sofrer violências ainda mais graves, dentre outras razões que somente a análise de casos concretos poderia elucidar.

No que se refere à proteção de crianças e adolescentes contra a violência intrafamiliar, além do Estatuto da Criança e do Adolescente - Lei $\mathrm{n}^{\circ} 8.069$ - que disciplina sobre a Doutrina da Proteção Integral e do Melhor Interesse da Criança, por exemplo, e enumera quais são os direitos fundamentais destes sujeitos de direitos destacando a prioridade absoluta com a qual estes direitos devem ser garantidos e efetivados, há Leis que tratam com maior especificidade as violências intrafamiliares que tem por vítimas crianças e adolescentes.

Desde já, tendo em vista que este estudo trata sobre as hipóteses de destituição do poder familiar, esclarecemos que a violência contra aqueles os quais o poder familiar recaía já era motivação para a destituição do poder familiar (o que será apresentado detalhadamente no próximo item), e justificamos o seu estudo neste artigo no fato de considerarmos que tanto crianças e adolescentes quanto as mulheres possuem vulnerabilidades específicas que contribuem fortemente para as violências sofridas por eles no âmbito doméstico e familiar.

Com o objetivo de proteger o direito da criança e do adolescente à convivência familiar saudável e de coibir atos intencionais por parte daqueles que exercem algum tipo de poder ou influência na criança ou adolescente que almejem o repúdio destes ao genitor ou que causem prejuízo ao estabelecimento ou à manutenção de vínculos com este (BRASIL, 2010, art. $2^{\circ}$ ). Os atos que almejam estes objetivos são chamados de "atos de alienação parental" e prejudicam a realização de afeto nas relações com o genitor e com o grupo familiar (BRASIL, 2010, art. $3^{\circ}$ ).

Quanto à criança vítima, os atos e alienação parental constituem "abuso moral e descumprimento dos deveres inerentes à autoridade parental ou decorrentes da tutela ou guarda" (BRASIL, 2010, art. 3º e nos casos de caracterização dos atos de alienação parental mediante ação autônoma ou incidental, o juiz poderá, dentre outras ações, declarar a suspensão da autoridade parental (BRASIL, 2010, art. $6^{\circ}$ caput $e$ VII).

A proteção da criança e do adolescente contra a alienação parental, portanto, deriva do reconhecimento da prática de se utilizar a prole no ataque ao outro genitor, o que pode ocorrer na constância do casamento/união/convivência do casal ou após o término da relação. 
Esta pratica, que pode ser realizada sem a total compreensão por parte do genitor alienador a respeito das consequências negativas no desenvolvimento da vítima é uma forma de violência intrafamiliar, que quebra o mito a respeito de que a família é apenas um ambiente de amor e paz, descortinando a face cruel da relação familiar, na qual as maiores vítimas são as crianças e os adolescentes.

O direito de crianças e adolescentes de serem educados e cuidados sem o uso de castigos físicos e degradantes, apesar de garantido mediante a doutrina da Proteção Integral, normatizada tanto na Constituição Federal vigente, no artigo 226, e no Estatuto da criança e do adolescente, é regido pela Lei $n^{\circ}$ 13.010/2014, dispositivo legal que modifica o Estatuto da Criança e do Adolescente e Lei de diretrizes e bases da educação (Lei n ${ }^{\circ}$ 9.394/1996).

A Lei $n^{\circ}$ 13.010/2014 ficou conhecida como "Lei do menino Bernardo", pois a motivação para a sua criação foi a violência sofrida e morte de uma criança de $11 \operatorname{anos}^{6}$, de forma que dentre outros acusados estão o pai e a madrasta da vítima. Esta lei tem caráter educativo e as medidas nela previstas são aplicadas pelo Conselho Tutelar.

A Lei em comento garante que "a criança e o adolescente têm o direito de ser educados e cuidados sem o uso de castigo físico ou de tratamento cruel ou degradante, como formas de correção, disciplina, educação ou qualquer outro pretexto" (BRASIL, 2014, art. $1^{\circ}$ ), de maneira que as sanções cabíveis em casos de descumprimento do que esta lei estabelece são: “encaminhamento a programa oficial ou comunitário de proteção à família; encaminhamento a tratamento psicológico ou psiquiátrico; encaminhamento a cursos ou programas de orientação; obrigação de encaminhar a criança a tratamento especializado e advertência" (BRASIL, 2014, art. $1^{\circ}$ ).

A breve apresentação das leis citadas acima almejou demonstrar que a existência tanto da violência intrafamiliar de mulheres quanto de crianças e adolescentes tem sido

\footnotetext{
${ }^{6}$ Bernardo Uglione Boldrini, de 11 anos, desapareceu em 4/4/14, em Três Passos. Seu corpo foi encontrado na noite de 14 do mesmo mês, dentro de um saco plástico e enterrado às margens de um rio em Frederico Westphalen. Edelvânia Wirganovicz, amiga da madrasta Graciele Ugulini, admitiu o crime e apontou o local onde a criança foi enterrada. Respondem ao processo criminal o pai de Bernardo, Leandro Boldrini, a madrasta do menino, Graciele Ugulini, e os irmãos Edelvânia e Evandro Wirganovicz. Eles serão julgados pelo Conselho de Sentença do Tribunal do Júri, onde os jurados decidirão se são culpados ou inocentes dos crimes de homicídio quadruplamente qualificado (Leandro e Graciele), triplamente qualificado (Edelvânia) e duplamente qualificado (Evandro), além de ocultação de cadáver. Leandro Boldrini também responderá pelo crime de falsidade ideológica. A denúncia foi aceita pelo Juiz de Direito Marcos Luís Agostini, então titular da Vara Judicial da Comarca de Três Passos, em 16/5/14. Os réus estão presos. Para mais informações sobre o caso, acessar: http://www.tjrs.jus.br/casobernardo/index.php.
} 
reconhecidas pelo legislativo, e que a destituição do poder familiar provocada por estas violências é um desdobramento da percepção de que o ambiente familiar, em certos casos, pode ser violento e esta violência causa danos ao desenvolvimento da prole, sendo esta prole as vítimas ou não.

Isto posto, no próximo item analisaremos os aspectos gerais do poder familiar e as hipóteses de sua perda, almejando apresentar aos leitores a Lei ${ }^{\circ}$ 13.715/2018 e a interpretar como sendo uma norma que reconhece existência e gravidade da violência intrafamiliar e que nesta forma de violência os maiores índices de vítimas se configura por mulheres, crianças e adolescentes, bem como os danos causados à prole ao presenciar a violência doméstica entre os genitores.

\section{A PERDA PODER FAMILIAR DISPOSTA NA LEI No 13.715/2018}

A Lei $n^{\circ} 13.715 / 2018$, que dispõe sobre hipóteses de perda do poder familiar pelo autor de determinados crimes contra outrem igualmente titular do mesmo poder familiar ou contra filho, filha ou outro descendente, altera o Código Penal, o Estatuto da Criança e do Adolescente e o Código Civil e se apresenta como a principal referência legislativa deste trabalho.

Esta mudança de paradigma a respeito dos limites impostos ao exercício do poder familiar teve início com a promulgação da Constituição Federal de 1988, que inaugurou tanto a doutrina da proteção integral quanto a doutrina da prioridade absoluta direcionadas à crianças e adolescentes, determinando também a corresponsabilidade entre a família, a sociedade e o Estado na garantia e efetivação dos direitos fundamentais, bem como na proteção contra qualquer forma de negligência, discriminação, exploração, violência, crueldade e opressão (BRASIL, 1988, art. 227).

A igualdade de gênero consagrada na Constituição Federal significou uma mudança sensível na maneira de se estabelecer o poder familiar e as relações familiares de forma geral, tendo em vista que "o Código Civil de 1916 assegurava o pátrio poder exclusivamente ao marido como cabeça do casal, chefe da sociedade conjugal. Na sua falta ou impedimento é que a chefia da sociedade conjugal passava à mulher, que assumia o exercício do pátrio poder dos filhos" (DIAS, 2017, p. 486). 
Especificamente no que tange ao poder familiar, o Estatuto da Criança e do Adolescente - Lei no 8.069/1990 disciplina que “o poder familiar será exercido, em igualdade de condições, pelo pai e pela mãe, na forma do que dispuser a legislação civil, assegurado a qualquer deles o direito de, em caso de discordância, recorrer à autoridade judiciária competente para a solução da divergência” (BRASIL, 1990, art. 21), de maneira que tal dispositivo legal, bem como os constantes do Código Civil a respeito do exercício do poder familiar ser exercido tanto pelo pai quanto pela mãe deve ser interpretado levando em consideração os casos nos quais o poder familiar é exercido por casais homoafetivos, sendo assim exercido por ambos os pais ou ambas as mães.

O poder familiar é disciplinado detalhadamente no Código Civil de 2002, determinando que os filhos estão sujeitos ao poder familiar, enquanto menores (BRASIL, 2002, art. 1.630), de maneira que a separação judicial, o divórcio e a dissolução da união estável não alteram as relações entre pais e filhos, senão enquanto ao direito, que aos primeiros cabe, de terem em sua companhia os segundos (BRASIL, 2002, art. 1.632). Ressaltamos que o poder familiar comporta em sua estrutura tanto poderes quanto deveres, sendo os primeiros limitados às normas de proteção à criança e ao adolescente.

Maria Helena Diniz conceitua o poder familiar como "um conjunto de direitos e obrigações, quanto à pessoa e bens do filho menor não emancipado, exercido, em igualdade de condições, por ambos os pais, para que possam desempenhar os encargos que a norma jurídica lhes impõe, tendo em vista o interesse e a proteção do filho" (DINIZ, 2018, p. 641), em harmonia e em respeito ao princípio da isonomia entre o homem e a mulher, consagrado no artigo $5^{\circ}$, inciso I, conjuntura na qual não faz mais sentido a figura do antigo pátrio poder.

O exercício do poder familiar consiste em deveres e poderes direcionados aos filhos menores, em observância às normas protetivas direcionadas à criança e ao adolescente, que balizam e limitam o exercício do poder familiar. De acordo com o artigo 1.634 do Código Civil,

compete a ambos os pais, qualquer que seja a sua situação conjugal, o pleno exercício do poder familiar, que consiste em, quanto aos filhos:

I - dirigir-lhes a criação e educação;

II - exercer a guarda unilateral ou compartilhada, nos termos do art. 1584;

III - conceder-lhes ou negar-lhes consentimento para casarem;

IV - conceder-lhes ou negar-lhes consentimento para viajarem ao exterior;

$\mathrm{V}$ - conceder-lhes ou negar-lhes consentimento para mudarem sua residência permanente para outro município; 


\begin{abstract}
VI - nomear-lhes tutor por testamento ou documento autêntico, se o outro dos pais não lhe sobreviver, ou o sobrevivo não puder exercer o poder familiar;

VII - representa-los judicial e extrajudicialmente até os 16 (dezesseis) anos, nos atos da vida civil, e assisti-los, após essa idade, nos atos em que forem partes, suprindolhes o consentimento.

VIII - reclamá-los de quem ilegalmente os detenha;

IX - exigir que lhes prestem obediência, respeito e serviços próprios de sua idade e condição.
\end{abstract}

Ainda sobre as obrigações inerentes ao exercício do poder familiar, aos pais incumbe o dever de sustento, guarda e educação dos filhos menores, cabendo-lhes ainda, no interesse destes, a obrigação de cumprir e fazer cumprir as determinações judiciais (BRASIL, 1990, art. 22). Portanto, neste artigo do Estatuto da Criança e do Adolescente podemos visualizar o poder familiar como, além de um poder, um conjunto de deveres direcionados à criação saudável e integral dos filhos.

Flávio Tartuce, de outra maneira, elabora um conceito de poder familiar baseado sobretudo no afeto e na colaboração familiar, da seguinte maneira: "poder familiar é conceituado como sendo o poder exercido pelos pais em relação aos filhos, dentro da ideia de família democrática, do regime de colaboração familiar e de relações baseadas, sobretudo, no afeto" (TARTUCE, 2018, p.513). Percebe-se, portanto, que as relações familiares atualmente são fundamentadas no respeito mútuo entre todos os seus integrantes, na igualdade entre os filhos e na igualdade de gênero, o que afasta definitivamente da legislação o regime patriarcal que foi predominante no passado.

Estas características contemporâneas do direito de família contribuem para o reconhecimento de limites impostos tanto pela lei quanto pela cultura no que se refere às violências praticadas no seio familiar, sendo esta prática uma das causas de destituição do poder familiar mediante determinação judicial.

A violência tratada neste estudo se refere à praticada de forma intrafamiliar, tanto contra as crianças e os adolescentes quanto contra as mulheres, as quais tem por consequência a perda do poder familiar por parte do agressor/a, ressaltando que a Lei $\mathrm{n}^{\circ} 13.715 / 2018$ aumentou as hipóteses de violência no que se refere às vítimas, alcançando não só as violências praticadas contra a criança e o adolescente, o que ainda será apresentado detalhadamente neste estudo.

Antes da modificação provocada pela Lei $\mathrm{n}^{\circ}$ 13.715/2018, de acordo com o artigo 1.138 do Código Civil, o pai ou a mãe, por ato judicial, perderiam o poder familiar quando:

I - castigar imoderadamente o filho; 
II - deixar o filho em abandono;

III - praticar atos contrários à moral e aos bons costumes;

IV - incidir, reiteradamente, nas faltas previstas no artigo antecedente;

$\mathrm{V}$ - entregar de forma irregular o filho a terceiros para fins de adoção.

A modificação trazida pela lei em comento ${ }^{7}$, foi incluída no parágrafo único do artigo transcrito acima, aumentando as seguintes hipóteses:

Parágrafo único: Perderá também por ato judicial o poder familiar aquele que:

I - praticar contra outrem igualmente titular do mesmo poder familiar:

a) homicídio, feminicídio ou lesão corporal de natureza grave ou seguida de morte, quando se tratar de crime doloso envolvendo violência doméstica e familiar ou menosprezo ou discriminação à condição de mulher;

b) estupro ou outro crime contra a dignidade sexual sujeito à pena de reclusão;

II - praticar contra filho, filha ou outro descendente:

a) homicídio, feminicídio ou lesão corporal de natureza grave ou seguida de morte, quando se tratar de crime doloso envolvendo violência doméstica e familiar ou menosprezou discriminação à condição de mulher;

b) estupro, estupro de vulnerável ou outro crime contra dignidade sexual sujeito à reclusão.

Interpretamos no sentido de que o inciso III do artigo 1.138 do Código Civil, que determina como uma das hipóteses para a destituição do poder familiar "praticar atos contrários à moral e aos bons costumes" já seria o suficiente para abarcar os casos de violência doméstica e familiar e os de feminicídio, bem como as violências praticadas contra os demais descendentes do agressor, todavia, a Lei $\mathrm{n}^{\circ}$ 13.715/2018 especificou tais crimes e os conferiu importância suficiente ao ponto de se enquadrar como causas da perda do poder familiar.

Consideramos que o legislador considerou as violências enumeradas acima como prejudiciais à convivência familiar harmoniosa e, principalmente, ao desenvolvimento psicológico e social das crianças e adolescentes, bem como que o detentor do poder familiar que pratica as violências enumeradas não tem condições de ser detentor do poder familiar, tanto pela influência que representa aos menores que estão aos seus cuidados quanto por

\footnotetext{
${ }^{7}$ A lei n ${ }^{\circ}$ 13.715/2018 também altera o Código Penal e o Estatuto da Criança e do Adolescente nos seguintes termos: Código Penal: Altera o inciso II do caput do art. 92.

II - a incapacidade par o exercício do poder familiar, da tutela ou da curatela nos crimes dolosos sujeitos à pena de reclusão cometidos contra alguém igualmente titular do mesmo poder familiar, contra filho, filha ou outro descendente ou contra tutelado ou curatelado.

Estatuto da criança e do adolescente:

Modifica o $\S 2^{\circ}$ do art. 23:

$\S 2^{\circ}$ A condenação criminal do pai ou da mãe não implicará a destituição do poder familiar, exceto na hipótese de condenação por crime doloso sujeito à pena de reclusão contra outrem igualmente titular do mesmo poder familiar ou contra filho, filha ou outro descendente.
} 
descumprir obrigações inerentes ao exercício do poder familiar. Para Kitzmann, a respeito das consequências negativas de se presenciar a violência doméstica:

Crianças expostas à violência doméstica estão em situação de risco devido a uma série de problemas psicossociais, mesmo quando não são alvo da agressão física. Esses problemas são semelhantes àqueles observados em crianças que sofrem abuso físico, o que sugere que qualquer tipo de violência na família pode prejudicar o desenvolvimento da criança (KITZMANN, 2007, p. 4).

Como já explicado acima, escolhemos apresentar certos sujeitos como vítimas da violência intrafamiliar, a ser: a criança, o adolescente e a mulher. Rolf Madaleno, a respeito do tratamento diferenciado direcionado a certos grupos afirma que "a vulnerabilidade é um traço universal de alguns grupos de pessoas existentes na sociedade e destinatários de especial proteção, justificando-se o tratamento diferenciado em razão das suas condições políticas, sociais e culturais" (MADALENO, 2018, p. 55), o que reafirma a maior possibilidade dos sujeitos citados acima serem vítimas de violências sofridas no meio familiar e doméstico.

A violência contra a mulher, bem como a violência contra crianças e adolescentes se apresentam como um problema presente em muitas residências brasileiras, como ilustrado no item anterior, ocasião na qual apresentamos dados estatísticos a respeito dos índices de violência doméstica e familiar e feminicídios registrados no país, ressaltando que os números apresentados não traduzem a realidade, tendo em vista que nem todas as violências em análise chegam a ser denunciadas, sendo estas vítimas as preferenciais, como explica Rolf Madaleno da seguinte forma:

Embora a Carta Política pregue a suprema proteção dos valores humanos, sob o enfoque da prevalência da dignidade da pessoa e por conta de cujo princípio sobressaia como incontestável fato natural a igualdade jurídica do homem e da mulher, ainda pende o modelo cultural da dominação masculina dentro da sociedade afetiva e ainda pende o modelo de discriminação etária no núcleo familiar (MADALENO, 2018, p. 52).

No que tange à violência contra crianças e adolescentes, a Lei $n^{\circ} 13.431 / 2017$, norma que estabelece o sistema de garantia de direitos da criança e do adolescente vítima ou testemunha de violência, apresenta um rol exemplificativo de tipos de violências as quais podem vitimar estes sujeitos, sendo eles: a violência física; a violência psicológica; o ato de alienação parental; a violência sexual, dividida entre abuso sexual, exploração sexual e tráfico de pessoas; violência institucional. 
Compreendemos no sentido de que, dos tipos de violência apresentados acima, a violência física, a violência psicológica, o ato de alienação parental e o abuso sexual podem ser os praticados intrafamiliarmente com mais frequência, tendo por consequência a perda do poder familiar do agressor. Entretanto, presenciar agressões físicas e verbais e em casos mais extremos o assassinato de um dos genitores pode ser tão danoso quanto a violência sofrida.

Por conseguinte, a Lei $n^{\circ} 13.715 / 2018$ contribui na prevenção e defesa deste tipo de violência, qual seja a sofrida pelos filhos ao presenciar violências perpetradas entre os detentores do poder familiar, ou seja, aqueles que exercem forte influência e por quem os filhos nutrem afeto.

Kitzmann, ao analisar a violência doméstica e seu impacto sobre o desenvolvimento social e emocional de crianças afirma que:

Há evidências de que crianças que presenciam violência doméstica correm risco de enfrentar diversos problemas psicossociais. Na verdade, os problemas observados nessas crianças são semelhantes àqueles observados em crianças que são vítimas diretas de abuso físico. Uma vez que testemunhar violência doméstica pode aterrorizar as crianças e perturbar significativamente sua socialização, alguns especialistas passaram a considerar a exposição à violência doméstica como uma forma de maus tratos psicológicos (KITZMANN, 2007, p. 2).

O contato com a violência, tanto na condição de vítima quanto na condição de testemunha, no que tange à criança e ao adolescente, em virtude da condição peculiar de ser humano em desenvolvimento e todas as peculiaridades desta fase etária, de acordo com as considerações de Kitzmann acima, podem causar danos de magnitude equivalentes, o que gera a necessidade de se protege-los de ambos tipos de vivências agressivas, sendo pertinente a inclusão explícita da hipótese de perda do poder familiar mediante a violência doméstica, sendo esta medida legislativa um alerta decorrente do reconhecimento da existência deste tipo de violência, o que pode, no futuro, promover políticas de enfrentamento e prevenção da violência doméstica, tendo como justificativa a proteção tanto da vítima quanto das crianças e adolescentes que convivem com a violência.

\section{CONCLUSÃO}

A violência tanto contra crianças e adolescentes quanto contra a mulher é caracterizada pela imposição da força e da influência sob a qual estão submetidos. Apresentamos neste estudo a violência intrafamiliar como peculiar no que tange à vitimação 
destes sujeitos, o que justificou o destaque dado às situações de violência no qual eles são suscetíveis de sofrer danos, tanto físicos - com a possível morte - quanto psicológicos.

Para demonstrar a veracidade das afirmações relativas à existência de violência doméstica em índices alarmantes, que tem por vítimas as mulheres, as crianças e os adolescentes apresentamos dados estatísticos e as leis que possuem o escopo de proteger estas vítimas, utilizando, dentre a apresentação destas leis de proteção duas que foram motivadas por casos reais de violências gravíssimas praticadas contra a mulher (Lei Maria da Penha Lei $^{\circ} 11.340 / 2016$ ) e contra a criança (Lei Menino Bernardo - Lei n $\left.{ }^{\circ} 13.010 / 2014\right)$.

Com esta análise demonstramos que a violência doméstica no Brasil é uma triste realidade, e que a sua prevenção e punição deve ser almejada pela sociedade, o que é certificado pela atuação legislativa a respeito deste problema social e de saúde pública.

A violência ocorrida dentro de casa tem por característica não afetar a penas a vítima, e sim todo o ambiente familiar e seus integrantes. Neste contexto estão as crianças e os adolescentes, que podem ocupar o lugar tanto de vítima quanto de testemunha das agressões e em casos extremos, porém não raros, a morte. Quando a prole é vítima de um dos detentores do poder familiar, seja de violência física, sexual, psicológica, dentre outras, justifica-se a perda do poder familiar do agressor, ou seja, daquele que descumpriu com os deveres inerentes ao exercício do poder familiar.

Igualmente, descumpre os deveres próprios do exercício do poder familiar quem violenta outros membros do ambiente familiar, aqui destacado o outro detentor do poder familiar, tendo em vista que para aquele sobre quem recai o poder familiar, a prole, os danos causados pela convivência em lares violentos, bem como pela exposição a estes atos pode se assemelhar aos danos causados quando estes são as vítimas, representando um importante fator de risco para a adequada interação social e desenvolvimento.

Portanto, se justifica a perda do poder familiar motivado pela prática de violência que vitime o outro detentor deste poder, pelo perigo que o agressor apresenta à prole; pela influência que exerce aos filhos e pelo direito inerente à criança e ao adolescente de viver em um lar seguro e a salvo de violências, sendo a efetivação deste direito uma obrigação da família, do Estado e da comunidade em geral, decorrendo do princípio da convivência familiar e comunitária, ou seja, mesmo nos casos em que a criança e o adolescente não são vítimas diretas da violência intrafamiliar, o serão de forma indireta. 


\section{REFERÊNCIAS}

BRASIL. Constituição (1988). Constituição da República Federativa do Brasil.

BRASIL, Lei no 8.069/1990. Dispõe sobre o Estatuto da Criança e do Adolescente.

BRASIL, Lei $\mathrm{n}^{\circ} 11.340$, de 7 de agosto de 2006. Cria mecanismos para coibir a violência doméstica e familiar contra a mulher, nos termos do $§ 8^{\circ}$ do art. 226 da Constituição Federal, da Convenção sobre a Eliminação de Todas as Formas de Discriminação contra as Mulheres e da Convenção Interamericana para Prevenir, Punir e Erradicar a Violência contra a Mulher; dispõe sobre criação dos Juizados de Violência Doméstica e Familiar contra a Mulher; altera o Código de Processo Penal, o Código Penal e a Lei de Execução Penal; e dá outras providências.

BRASIL, Lei $\mathrm{n}^{\circ} 12.318$, de 26 de agosto de 2010. Dispõe sobre a alienação parental e altera 0 art. 236 da Lei ${ }^{\circ}$ 8.069, de 13 de julho de 1990.

BRASIL, Lei ${ }^{\circ} 13.010$, de 26 de junho de 2014. Altera a Lei $\mathbf{n}^{\circ} \mathbf{8 . 0 6 9}$, de 13 de julho de 1990 (Estatuto da Criança e do Adolescente), para estabelecer o direito da criança e do adolescente de serem educados e cuidados sem o uso de castigos físicos ou de tratamento cruel ou degradante, e altera a Lei $\mathbf{n}^{\circ}$ 9.394, de 20 de dezembro de 1996.

BRASIL, Lei $\mathrm{n}^{\circ} 13.431$, de 4 de abril de 2017. Estabelece o sistema de garantia de direitos da criança e do adolescente vítima ou testemunha de violência e altera a Lei $\mathbf{n}^{\mathbf{0}} \mathbf{8 . 0 6 9}$, de 13 de julho de 1990 (Estatuto da Criança e do Adolescente).

BRASIL, Decreto $n^{\circ}$ 9.603, de 10 de dezembro de 2018. Regulamenta a Lei $\mathbf{n}^{\mathbf{0}}$ 13.431, de 4 de abril de 2017, que estabelece o sistema de garantia de direitos da criança e do adolescente vítima ou testemunha de violência.

BRASIL, Lei $\mathrm{n}^{\circ}$ 13.104, de 9 de março de 2015. Altera o art. 121 do Decreto-Lei $\mathbf{n}^{\mathbf{0}} \mathbf{2 . 8 4 8}$, de 7 de dezembro de 1940 - Código Penal, para prever o feminicídio como circunstância qualificadora do crime de homicídio, e o art. $1^{\circ}$ da Lei $\mathbf{n}^{\circ} 8.072$, de 25 de julho de 1990, para incluir o feminicídio no rol dos crimes hediondos.

DIAS, Maria Berenice. Manual de Direito das Famílias. $12^{\circ}$ edição, revista, ampliada e atualizada. Revista dos Tribunais. 2017.

DINIZ, Maria Helena. Curso de direito civil brasileiro: direito de família. v. 5, 32. ed. São Paulo: Saraiva, 2018

MADALENO, Rolf. Direito de família. 8. ed., rev., atual. e ampl. Rio de Janeiro: Forense, 2018. 
MADALENO, Rolf. Manual de direito de família. Rio de janeiro: Forense, 2017.

TARTUCE, Flávio. Direito civil, v. 5: direito de família. $13^{\circ}$. ed. Rio de Janeiro: Forense, 2018.

TRINDADE, Jorge. Manual de psicologia jurídica para operadores do direito. $8^{\circ}$ ed., rev., atual. e ampl. Porto Alegre: Do advogado, 2017.

KITZMANN, Katherine M. Violência doméstica e seu impacto sobre o desenvolvimento social e emocional de crianças pequenas. University of Menphs, EUA. Agosto de 2007, Ed. rev. 